\title{
The outsourcing of social care in Britain: what does it mean for voluntary sector workers?
}

\begin{abstract}
While recent decades have witnessed a growth in the outsourcing of public services in Britain, the post-1997 UK Labour governments have sought to put in place mechanisms aimed at encouraging long-term collaborative contracting relationships marked by less reliance on cost-based competition. This article explores empirically how far these mechanisms have achieved their aims, and thereby acted to protect the employment conditions of staff, and links this exploration to debates concerning the employment implications of organisational reforms within public sectors internationally. It concludes that in terms of bringing income security to the voluntary sector and stability to employment terms and conditions these efforts have been unsuccessful, and consequently casts doubts on more optimistic interpretations of the employment effects of organisational restructuring in the British public sector.
\end{abstract}

Keywords: job security, marketisation, outsourcing, social care, terms and conditions, voluntary sector, work intensity

\section{Introduction}

The outsourcing of public social care services to private and not-for-profit organisations has continued unabated in Britain over the last quarter of century. Pursued by the Conservative governments during the period 1979-1997, its usage has remained a key feature of governmental agenda under the post-1997 Labour ones. Indeed, it has expanded considerably during this latter period, to the point where more than 50 percent of social care hours are now provided by staff working for such organisations (Scottish Executive, 2005). This more recent expansion has, however, occurred against the backcloth of policy initiatives aimed at replacing the type of short-term, cost-based, contracting which occurred under Compulsory Competitive Tendering (CCT) with longer-term 'partnership' relationships. 
Against this background, the present article uses new empirical findings, obtained from a recent project funded by the public sector union Unison, to examine whether this changing environment of contracting is encouraging longer-term stable partnerships and thereby acting to protect employment conditions in the UK voluntary sector. This focus is of interest for two inter-related reasons. First, it links into broader debates among international scholars concerning the outcomes of inter-organisational relations in terms of their structures (Adler, 2001) and consequences for employment conditions (Marchington, et al, 2005) within advanced economies and public sectors in particular (Considine, 1996: Scofield, 2001). Secondly, and more narrowly, it also relates to a growing academic interest in OECD countries as to how the resulting growth in the role of the non-profit/voluntary sector in service delivery is acting to affect employment relationships within it (see Baines, 2004; Bode, 2004: Onyx and Maclean, 1996).

The paper is divided into four main sections. In the first, a brief overview is provided of the evolution and current nature of the British social care market place and attention paid to the potential employment-related implications of recent developments in it and related theoretical debates. The next two go on to detail the methodology of the recent Unison sponsored study and its central findings. Finally, the last, concluding, section draws together the key conclusions emerging from the provided evidence and identifies issues worthy of further research.

\section{Outsourcing in the British social care sector and its employment implications}

The development of the British welfare state in the immediate post-war era was accompanied by the delivery of public services by large scale, state run, hierarchical bureaucracies, where control over decisions lay with the centre, and local discretion was exercised informally (Walsh, 1995). From the 1980s, however, radical changes to this mode of delivery occurred (Batsleer, 1995). These changes, initially, stemmed from the ideological shift which followed the election of the 1979 Thatcher government that encompassed an acceptance of 'New Right' critiques that the welfare state was poorly managed, unaccountable, professionally dominated and lacking client involvement due to an absence of market incentives and pressures (Walsh, 1995: Osborne, 1997). Thus, on the basis of this analysis, successive 
Conservative governments during the period to 1997 sought to create a mixed economy of welfare under which local and health authorities changed from being monopoly providers of care to becoming the planners, commissioners and monitors of services contracted out to non-statutory providers in the private and voluntary sectors (Harris et al, 2001).

This emphasis on sub-contracting by local and health authorities has not only continued but increased in the period since the election of the Blair government in 1997 (Davies, 2007). It has, however, in terms of policy rationale, been supported by 'third way', rather than New Right, inspired prescriptions regarding public sector reform.

Initially, this apparent shift of philosophical approach was accompanied by a policy approach that, at least at the rhetorical level, placed an emphasis on "what matters is what works' and consequently embodied no firm view regarding whether services were best provided through public or independent providers. Latterly, however, there has been an increasing shift towards services being delivered by independent private and non-profit organisations under competitive quasi-market conditions (Geddes, 2001).

At the same time, post-1997 Labour governments have also placed more emphasis on the establishment of 'obligational', rather than 'arms length', transactional relationships with voluntary sector providers that are less underpinned by price-based competition (Sako, 1992; Marchington et al, 2005). In turn, a number of regulatory changes have been utilised to support the development of such client-provider relationships. Of particular note in this regard, has been the production of a 'Compact' code of practice (Home Office, 2005). A code which echoes the commitments given in a 2002 Treasury Cost-Cutting Review on 'The Role of the Voluntary and Community Sector in Service Delivery' to 'implement longer term funding arrangements where these represent good value for money' and to accord recognition to the fact that 'it is legitimate for voluntary and community organisations to include the relevant element of overhead costs in their estimates for providing a particular service' (HM Treasury, 2002). 
This code, along with the greater emphasis placed on service quality relative to price competitiveness within the local government Best Value regime (Roper et al, 2005), would seem at first sight to provide a policy context that is facilitative of a social care market place marked by a reduced tendency to drive down the job security, and terms and conditions, of those employed by contracting voluntary organisations. Particularly given that these developments have occurred alongside the promulgation by the government, in response to union concerns about the way in which market competition was acting to drive down the terms and conditions of contractor staff, of a Code of Practice on Workplace Matters. The effect of which is to require most types of public bodies to ensure that staff employed to work on outsourced contracts alongside transferees from the public sector are provided with terms and conditions that are no less favourable than those of the latter.

This positive interpretation of the employment-related implications of outsourcing to voluntary sector organisations is, though, one that can be seen to be open to question given that their nature will be inevitably shaped not only by surrounding government policies, but also the wider market place within which outsourcing contracts are concluded. Particularly when it is borne in mind that public sector markets are marked by monopsony purchasers who have the power to dictate the 'rules of the game' (Hoggett, 1996), with all that this entails in terms of the nature of competition within them and the extent to which it is cost-based. Evaluations of the impact of Labour's Best Value initiative, for example, have identified, notwithstanding its focus on quality, a continuation of the liberalising agenda of 'more for less' with related detrimental consequences for terms and conditions of employment (Geddes, 2001: Richardson et al, 2005).

These different interpretations of the present Labour government's approach to the outsourcing of social care provision can, in turn, be linked to broader debates concerning the nature and dynamics of inter-organisational relations and their employment consequences. In particular, the notion that there are many different types of inter-organisational relations that encompass a range of hybrid intermediate forms which are neither purely 'arms length' or 'obligational' (Sako, 1992), but, rather, embody varying combinations of 'hierarchy', 'trust' and 'market' (Adler, 2001). 
Against this background, in the public sector, debates have moved on from notions of 'post-bureaucracy' to evaluating the degree to which bureaucracy still pervades (Scholfield, 2001: McSweeney, 2006) in recognition of the emergence of hybrid intermediate forms of organisation in the sector (Considine, 1996). One such hybrid form, labelled the 'market bureaucracy' (Considine, 1996), is particularly useful in evaluating outcomes from the purchaser-provider relationship between state and voluntary sector in the UK in the New Labour era. The concept of the 'market bureaucracy' places competition at the centre of relations between public sector organizations and their suppliers, and embodies the view that the devolution or outsourcing of services to competing organizations is centrally concerned with shedding public sector organisations of their staff and capital costs. The subsequent contracts between purchaser and providers are consequently seen to be 'arms-length' in nature, based on price and marked by a lack of promise of further employment or a shared future, while also containing highly detailed and transparent job or task specifications, and requirements regarding performance standards and continuous improvement.

Such relations can be seen to resemble those established under previous Conservative governments which prompted the view that outsourcing had an inherent tendency to intensify work and drive down terms and conditions below those prevailing in the public sector (Cousins, 1988). Such inter-organisational forms and their employment outcomes consequently provide a useful contrast to the aforementioned rhetoric of contracting arrangements espoused by the Labour government in relation to the voluntary sector. In doing so, this contrast raises two important empirical questions. First, to what degree are the types of contractual relations advocated in the rhetoric of New Labour governments being utilised? Secondly, how far is this current contracting practice leading to employment related outcomes that differ in nature to those which occurred under the pre-1997 Conservative government market based reforms?

\section{Research methodology}

The trend towards the outsourcing of social care is an issue of central strategic interest to the public sector union Unison, not only because of its obvious implications for 
members working in the area within local authorities and the National Health Service but also because the voluntary sector represents one of its fastest growing sources of new membership (Unison, 2006). As a consequence, the union commissioned the authors to undertake research on two inter-related themes that are relevant to the earlier reviewed theoretical and policy terrain. These are:

(a) To what extent is the current social care market marked by longer term contractual relationships embodying greater financial stability and security for voluntary organisations?

(b) How far is New Labour's 'third way' quasi-market acting to support employment regimes within voluntary organisations which are conducive to the protection of the job security, terms and conditions and well-being of staff working in them?

The study concerned was conducted in two phases. In the first, the impact of the emerging contract culture in social care was explored through the obtaining of employer and union perspectives on its implications. In the case of the former perspectives, these were gained from 12 voluntary organisations in which Unison either was recognised for the purposes of collective bargaining (6 cases) or had some membership presence but not full recognition, and that provided a variety of different types of services: children's services (two cases), housing associations (two cases), community health (one case), adults with learning difficulties (two cases), mental health problems (one case), the elderly (one case), advisory centres for a range of vulnerable groups (one case), the homeless (one case), and services for disabled people (one case).

In terms of their workforce numbers, four of these participating organisations had workforces of less than twenty, with the smallest employing ten, and five organisations had workforces of less than five hundred, with the smallest of these employing 30 and the largest approximately 360 . The remainder employed over five hundred staff, with the largest employing approximately nine hundred. 
The employer based data were obtained in two ways. The first involved contacting a senior manager in each organisation, usually a Chief Executive, or senior director, with a request to complete a short questionnaire asking for background information on areas such as income, funding sources, duration of contracts, and the management of funding applications, as well as various workforce data. Face-to face interviews were then conducted using a series of prepared questions but also probing for information as a result of the data supplied in the initial questionnaire. The interviews focussed on issues pertinent to the wider theoretical debates of contracting out and Unison's own agenda for its membership in the sector. Interviews thus encompassed questions that sought to gain an understanding of the climate of purchaser - provider relations through exploring perceived trends in the extent and costs of contracting and their links with forms of workforce insecurity, changes to pay and conditions and the quality of care.

As regards the obtaining of union perspectives, qualitative interviews were held with one national official, and four regional activists based respectively in England, Wales, Scotland and Northern Ireland, who were selected on the basis of their specialist roles in servicing and organising within the voluntary sector, and further ones undertaken with five workplace activists and three branch officials. Again, these interviews sought opinions on the climate of purchaser - provider relations and its impact on working conditions in the voluntary sector.

The aim of the second phase of research was to gain a more direct impression of the impact of the insecure funding environment on employees. To this end, it entailed interviews with lay activists in three of the above organisations and the holding of a focus group in each of them containing between 6-12 union and non-union members of staff. The specific themes explored during the course of these focus groups were developments in pay, job security and roles, working time and health and safety protection, and the way in which such developments were impacting on worker morale.

The first of these organisations was a small voluntary organisation working in the area of children's services, given the name Astro, which had 19 staff and one or two Unison members. The second a large provider of services to adults with learning 
difficulties (600 staff), referred to as Merlin here, which had 600 staff, union recognition, approximately $40 \%$ membership density, a shop-steward committee structure and a consultative forum which also contained non-union representatives. The last a user-led small/medium sized organisation specialising in services promoting inclusive living for disabled people, which is given the name Telstar for present purposes, and had 30 staff, union recognition, with 70 percent membership density and one shop steward.

All data from the interviews and focus groups from the two phases of research were taped and fully transcribed. The analysis of the data obtained was influenced by the general analytical procedure favoured by Miles and Huberman (1994). Thus, it began with the referencing of interviews, observations and documents on summary sheets. Then, the subsequent process of coding the data involved creating a 'start-list' of codes around the themes of purchaser - provider relations, funding insecurity, pay and conditions, work intensification and workforce insecurity. These codes were then applied to the data in relation to the individual research questions.

\section{The social care market place and its implications for staff}

In exploring the climate of relations between purchasers and providers, the findings generally revealed the existence of relationships which were far removed from the type of 'obligational', or partnership, contracting identified earlier. Thus, only one of the 12 management interview respondents reported that a significant proportion of their organisation's funding from government sources was now provided on a three yearly basis, four reported that there had been no movement whatsoever in this direction, and the remainder indicated that their funding consisted of contracts and grants that were renewed over a period of between one and three years. In addition, their responses indicated clearly that the application of the principles of 'full-cost recovery' remained limited and, more generally, suggested that the extent and intensity of competition in the social care market place were increasing, and that the financial climate within it was deteriorating markedly. It also emerged strongly that this deteriorating financial climate was not just a product of competitive pressures but also an outcome of the financial pressures under which service commissioners were operating. 
The findings obtained in relation to recent developments with regard to work intensity, job security and terms and conditions of staff echoed substantially, as is detailed below, those reported above regarding the nature of the current social care market place.

\section{Pay and conditions}

Traditionally, many voluntary organisations have linked their pay to Local Authority National Joint Council scales. Eight of the 12 organisations visited were found to still retain this linkage. The retention of it in a number of these was, though, seen to be problematic. Several of the smaller organisations, for example, felt that the continuation of linking pay to local authority scales was essential to retain competitiveness in the labour market, but also pointed out that its maintenance was dangerous since the annual funding uplift usually did not cover the full cost of local authority increases, with the result that several of them needed, on occasion, to draw from donated voluntary income and reserves to cover annual pay rises. The Chief Executive of one of these smaller organisations, for example, stated in relation to this that:

'We are starting to run at a loss now and you don't know how long you can do it because you know the reserves are there for a purpose, for redundancy and stuff like that. If things don't improve there will be a reduction in service, but eventually that reduction cannot reach a certain level beyond which you can't operate. In the long term this might actually destroy us...we are quite small. We are very vulnerable.'

Larger organisations were also vulnerable to changes to pay and conditions. One workplace activist reported how, at the time of the interviews, the housing association in which he was employed was proposing to move away from NJC scales. If these proposals went through, because no 'red circling' would occur, support workers would move five points down the NJC scale and the rest of the staff two points. According to the activist, management's rationale for this proposal was based on the 
assumption that competition for Supporting People ${ }^{1}$ funding would increase in the future, making the organisation's attachment to NJC scales uncompetitive in the market.

A manager from a housing support organisation similarly reported how discussions had occurred at board level regarding moving from NJC scales because of the risks of deficits arising as a result of inflationary uplifts from funders being insufficient to cover increases in them, although no action had so far been taken in this direction. More generally, in Unison's housing association branch, the respondent reported how she feared that this type of move would be common across the sub-sector given the continuation of cuts in the Supporting People programme.

\section{Job insecurity and work intensity}

A remarkably consistent picture emerged from both phases of the research concerning how the current contract culture in social care was intimately connected to increased levels of employment insecurity. All the regional organisers interviewed, for example, identified organisations out with of the study which had made redundancies because of the loss of significant contracts. In addition, all but one or two of the employer respondents reported how they had, in recent years, made redundancies in certain projects because of funding cuts and all of them reported how, due to insecure funding, they had experienced situations where groups of their employees had been under the threat of redundancy.

Redeployment appeared to be commonly used to mitigate the consequences of such insecurity. It, though, was not without its problems and in some cases merely acted to create other, sometimes broader, forms of insecurity. In particular, it was highlighted how the use of redeployment was, in fact, leading on an occasion to an increase in the degree of flexibility expected of staff, as the following quote from a senior manager in one of these organisations illustrates:

\footnotetext{
${ }^{1}$ Since 2003 'Supporting People' has replaced Housing Benefit and other funding streams in the UK as the means for meeting the costs of housing and support services for a range of vulnerable people. It is administered by local authorities.
} 
'We have got well away from any sense that they have a particular place of work or a particular boundary around what they will do. You generally feel that the core competencies of our front line workers are similar. So if you are a support worker in a care home you could probably be a good support worker in a housing support role and be a good one with children and young people...we have encouraged that and felt that it was the right response to the external pressure.'

There was also evidence to suggest that there was a degree of additional concern among vulnerable groups in the labour market such as the disabled and older workers as a result of worries about their being unable to secure alternative employment if their contracts came to an end.

The evidence further suggested that work intensification had occurred across all grades of staff. A Unison activist, for example, revealed how it was common for funding decisions to lead to a restructuring of management roles. This in some cases would lead to a reduction of front line managers, with consequent increases in the spans of control of those who remained and the reallocation of managerial functions to more junior staff. In a similar vein, it was reported in one housing association that a whole grade of deputy manager posts had been removed and that this had led to significant knock-on consequences for the workloads of some front line workers because these managers had previously been responsible for covering the work of absent staff.

In relation to this intensification of management roles, a senior manager in Merlin pointed to the difficulties faced by isolated, overworked and stressed project managers who were unable to receive needed support, such as personal training and development, because of insufficient resources. This same respondent also went on to note that such difficulties had led to several newly promoted managers approaching the organisation about going back to being a front-line worker.

A regional organiser and several employers noted that work intensification could also be a problem for support workers and those in administrative roles, a point that was also vividly highlighted in some of the exchanges within the focus groups. A case in 
point was that held within Merlin. Here, management had recently needed to make economies due to funding cuts and, in an attempt to avoid a direct impact on service users, had decided to reduce resources to certain administrative functions. In commenting on this reduction, one administrative worker noted that not only did it usually involve redundancies that were in themselves stressful enough but that once they had occurred the remaining employees were then required to absorb the responsibilities of the people who had lost their jobs, with no extra reward. Another respondent in the focus group, meanwhile, was extremely emotional when she stated:

'I am coping at the moment...to be quite honest I am not sure how it's going to go. I actually feel quite stressed...You know it was a full time job now I am doing seven days work. Seven days to fit into five...you hear somebody is not being replaced and then you then think am I going to be taking this on as well.'

The dynamics underlying these indications of work intensification were, in turn, usefully highlighted by a regional official from Scotland who reported that some inspections of services in his region started from the premise of making cuts of around four to six percent, or, alternatively, expecting providers to increase services by these amounts with the same level of staffing. In relation to this, he went on to further observe that:

'Organisations will say well this is my cake and it's the same size cake as last year, but I will still have to deliver what I did last year, plus whatever I have been given to deliver extra.'

\section{Conclusion}

The outsourcing of public social care services to voluntary organisations has intensified under the post-1997 Labour governments. This encouragement of outsourcing has occurred, however, against the background of attempts by government to put in place a regulatory framework intended to support a social care market place marked by longer-term partnership contracting which provides a greater 
degree of financial stability and security to voluntary organisations engaged in the delivery of such services.

Against this background, the present article has utilised new empirical findings, to shed light on (a) the extent to which the current social care market is, indeed, marked by longer term contractual relationships embodying greater financial stability and security, and (b) the degree to which it is, as a consequence, acting to support employment regimes within voluntary organisations which are conducive to the protection of the job security, terms and conditions and well-being of staff working in them.

The conclusions arising from the analysis are pessimistic in nature. Thus, it reveals that there has been little move by service funders to conclude longer term contracts with voluntary sector organisations, or to fund such contracts on the basis of 'full cost recovery' and, also points to a market place characterised by growing financial pressures and insecurity. As a result, the findings obtained have served to reinforce those of other studies that have explored the current climate of purchaser - provider relations existing between state and voluntary sector bodies (Alcock et al, 2004; National Audit Office, 2005; Charity Commission, 2007).

More generally, the findings obtained can be seen to add further support to those who argue that the processes associated with the outsourcing of public services have an inherent tendency to intensify work and drive down terms and conditions, while engaging workers in tightly prescribed tasks (Baines, 2004: Baines, 2005). They further suggest that relations between state and voluntary sector in the UK, and the employment outcomes associated with them, resemble that of the market bureaucracy (Consadine, 1996) rather than the 'partnership' type arrangements espoused by successive Labour governments since 1997.

It nevertheless needs to be recognised that, given the relatively small scale nature of the study reported here, its findings cannot be assumed to be representative of developments in the British voluntary sector as a whole, let alone those occurring within other developed economies where a similar trajectory of the sector playing a greater role in social care provision is apparent. This is particularly so when it is borne 
in mind that other studies of 'partnership' relationships between purchasers and suppliers within and across sectors have shown how more positive relationships and employment outcomes can develop in situations where there is a relatively low dispersion of power and a reasonable balance of risk sharing between the two contracting parties, and the consequent existence of a good deal of mutual trust (Marchington et al, 2005).

There consequently seems scope for further research to be undertaken on the employment outcomes of outsourcing in the social care sector aimed at addressing this issue of generalisability. For example, given the aforementioned results reveal conditions may be worse within the Supporting People programme, there would seem a need for studies to be undertaken across different service areas and particular funding regimes in order to explore how far they are marked by rather different employment related effects and, insofar as they are, why this is the case. In addition, comparative work could usefully be conducted to identify how far different national institutional settings are associated with differences in both the nature of contracting relationships and employment outcomes. Finally, and more generally, such further work could usefully be supplemented by studies centred on exploring, both at the domestic and comparative levels, the degree to which voluntary organisations are following the public sector path in moving from high commitment (Zimmeck, 1998) to low commitment, but high output, based employment relationships and, insofar as they are, how this change is impacting on service quality.

\section{References}

Adler, P. (2001) 'Market, Hierarchy and Trust: The Knowledge Economy and the Future of Capitalism', Organization Science, 12(2): 215-34.

Alcock, P., Brannelly, T and Ross, L. (2004) Formality or Flexibility? Voluntary Sector Contracting in Social Care and Health. London: NCVO.

Baines. D. (2004) 'Caring for Nothing: Work Organization and Unwaged Labour in Social Services", Work, Employment and Society,18(2): 267-295. 
Baines, D. (2005) 'Criminalizing the Care Work Zone? The Gendered Dynamics of Using Legal and Administrative Strategies to Confront Workplace Violence', Social Justice 32(2): 132-150.

Batsleer. J. (1995) 'Management and Organisation', in J.S. Smith, C. Rochester and R. Hedley. R (eds), An Introduction to the Voluntary Sector,pp. 224-248. London: Routledge.

Bode, I. (2004) 'The Quality of Nonprofit Employment - Patterns and Dynamics of Work Organization in the German Third Sector', in C. Stecker and A. Zimmer (eds), Strategy Mix for Nonprofit Organizations: Vehicles for Social and Labour Market Integration, pp. 227-245. New York: Kluwer Academic / Plenium Press.

Charity Commission. (2007) Stand and Deliver: The Future for Charities providing Public Services. London: Charity Commission.

Considine, M. (1996) 'Market Bureaucracy? Exploring the Contending Rationalities of Contemporary Administrative Regimes', Labour and Industry, 7(1): 1-28.

Cousins, C. (1988) Controlling Social Welfare: A Sociology of State Welfare and Organization. Sussex: Wheatsheaf Books.

Davies, S. (2007) Third Sector Provision of Local Government and Health Services. London: Unison.

Geddes, M. (2001) 'What about the Workers? Best Value, Employment and Work in Public Services', Policy \& Politics, 29(4): 497-508.

Harris. M., Rochester, C. and Halfpenny. P. (2001) 'Voluntary Organisations and Social Policy: Twenty Years of Change', in M. Harris and C. Rochester (eds), Voluntary Organisations and Social Policy in Britain: Perspectives on Change and Choice, pp.1-20: Basingstoke: Palgrave. 
HM Treasury. (2002) The Role of the Community and Voluntary Sector in Service Delivery: A Cross Cutting Review. London: HM Treasury.

Hoggett, P. (1996) 'New modes of Control in the Public Service”, Public Administration, 74(1): 9-32.

Home Office. (2005) Funding and Procurement: Compact Code of Good Practice. London: Home Office.

Marchington, M., Grimshaw, D., Rubery, J. and Willmott, H. (2005) Fragmenting Work: Blurring Organizational Boundaries and Disordering Hierarchies. Oxford: Oxford University Press.

McSweeney, B. (2006), 'Are we Living in a Post-Bureaucratic Epoch?', Journal of Organizational Change Management, 19(1): 22-37.

Miles, M.B and Huberman, A.M. (1994) Qualitative Data Analysis, $2^{\text {nd }}$ Edition. London: Sage.

National Audit Office. (2005) Working with the Third Sector. London: NAO.

Onyx, J. and Maclean, M. (1996) 'Careers in the Third Sector', Nonprofit Management \& Leadership, 6(4): 331-345.

Osborne, S.P. (1997) 'Managing the Coordination of Social Services in the Mixed Economy of Welfare: Competition, Cooperation or Common Cause?', British Journal of Management, 8: 317-328.

Richardson, M., Tailby, S., Danford, A., Stewart, P. and Upchurch, M. (2005) 'Best Value and Workplace Partnership in Local Government', Personnel Review, 34(6): 713-728. 
Roper, I., Higgins, P. and James, P. (2005) 'Workplace Partnership and Public Service Provision: The Case of the "Best Value" Performance Regime in British Local Government', Work, Employment and Society, 19(3): 639-649.

Sako, M. (1992) Prices, Quality and Trust: Inter-firm relations in Britain and Japan. Cambridge: Cambridge University Press.

Scottish Executive. (2005) Scotland's Social Care Labour Market. Edinburgh: National Workforce Group.

Schofield, J. (2001) 'The Old Ways are the Best? The Durability and Usefulness of Bureaucracy in Public Sector Management', Organization 8(1): 77-96.

Unison (2006) www.unison.org.uk/voluntaryindex. accessed 19.5.06.

Walsh. K. (1995) Public Services and Market Mechanisms. Basingstoke: Macmillan.

Zimmeck, M. (1998) To Boldly Go: The Voluntary Sector and Voluntary Action in the New World of Work. London: Royal Society of Arts. 